\title{
Application Analysis of Electrical Automation in Building Intelligent Systems Development
}

\author{
Shuangxi Zhang ${ }^{1, \text { a }}$ \\ ${ }^{1}$ Tieling Jinshi Real Estate Co. Ltd, Tieling, China, 112000 \\ ${ }^{a}$ email,
}

Keywords: Application Analysis, Electrical Automation, Building Intelligent Systems, Development

\begin{abstract}
Building intelligent systems is the automated control systems of construction equipment. Currently electrical automation technology gets more and more applications in modern buildings. The applications of electrical automation systems in intelligent building includes providing basic survival with plenty of electrical and mechanical equipment required environment for building services such as HVAC equipment, substation equipment, lighting equipment, as well drainage equipment and other equipment, through the realization of intelligent devices, to achieve the rational use of the equipment, to maximize energy savings and manpower to ensure the safety of equipment operation. This is the crux of the electric automation system in intelligent building applications, are described herein below on the electrical system in the intelligent building automation of key applications.
\end{abstract}

\section{Introduction}

Intelligent building typically includes many aspects of building automation, communications automation and office automation. With the rapid development of national economy, high-grade intelligent building has become the mainstream of today's buildings. Building Automation System is referred to as the building automation control systems. Construction equipment mainly refers to the construction and services, that a large number of electrical and mechanical equipment required environment provide people's basic living, such as HVAC, lighting, power distribution equipment as well as water supply and drainage equipment, building automation by implementing controls to achieve a reasonable use of equipment, save energy, save manpower, to ensure the safe operation of the destination device. Electrical automation building automation system has become an indispensable basic aspect. In building automation systems, electrical automation system design plays an important role. A few years ago people referred to the building automation system, referring mainly HVAC system automation system, and the current automatic control system has covered all controllable electrical equipment, electrical automation building automation system is already one of the most basic parts. In this article for electric automation in intelligent building applications are discussed.

\section{The Development of Building Intelligent Technology Research}

Intelligent Building Electrical is a product of the information age, at the same time, with the development of intelligent building technology, the natural extension of its concepts, in addition to having the characteristics of intelligent building this property, but also extends to the intelligence community and intelligent housing and other aspects.

The history of the development of intelligent building is dating back to the late 19th century. At that time, in order for the heating, ventilation, electricity and other control devices, some companies in Western Europe and the United States produced a mechanical controller and electrical controls. After the progress of science and technology in promoting mutual industrial process control applications, the controller constantly upgrading in the early 1950s, some European and American countries on the use of electronic devices in the building control system composed of various instruments, lights and operating lines connected to the case through various dispersed on-site electrical and mechanical equipment, used to centrally monitor the operation of equipment, and 
various electrical and mechanical systems for manual or automatic control.

In the 21st century, due to the rapid development of Internet, computer network technology, database technology has been applied in intelligent systems, allowing the development of intelligent systems and integrated systems to the network era. Since the technology has been widely used Web-based enterprise networks Intranet, intelligent system as a real-time control network enterprise architecture, it is an important source of information inside the enterprise. Intelligent system central station embedded Web server, enabling integration of intelligent system to become Web-enabled direction of the current system development. Integration of the system with the Intranet system is a server system should be transformed into Web-based modes, giving Web network management technology, Intranet authorization form to customers through WWW monitoring and management of intelligent devices throughout the system, so that the traditional independent system becomes part of the Intranet, the system is web-based network. We could say that the development of technology with the development of computer technology and network technology level and follow the development.

In intelligent residential district and intelligent technology, the development of the industry has gone through four stages: (a) in the early 1980s "Residential Electronic" (HE, Home Electronics): development of electronic technology has brought a large number of applications for home appliances. Typical system products: TV, refrigerator, washing machine, telephone, electric cookers. (b) the mid-1980s, "home automation" (HA, Home Automation): the development of communications and control technology to home appliances, communications equipment, security, disaster prevention equipment separate function integrated as one. (c) the 1990s into the "Home Network" (HN, Home Network): the United States called Smart house (WH, Wise House), known as the European fashion houses (SH, Smart House) due to the development of communication and network technology, the emergence of residential variety of home appliances, communications equipment, security equipment via bus technology HBS (Home bus system, such as the RS485 bus, CAN, LONWORKS) for monitoring, control and management systems. Typical system products: the use of bus technology, the traditional home appliances, lighting control systems; traditional video intercom systems, security systems, remote meter reading system. (d) 21 century into the "housing information": due to the rapid development of the Internet, integrated digital services network, a satellite communications network technology and telecommunications technology, networking, information technology has become the main form of intelligent home and today's scientific and technological research current the forefront. The emergence of home appliances, small home (personal) information with external devices connected Internet WAN connections with remote monitoring and control system. Typical systems Product: Ethernet intelligent terminal system, network appliances (refrigerators network, the network air conditioning, washing machine network, network water heaters, microwave network, network cookers), information appliances (including the PC, set-top boxes, HPC, DVD, Super VCD, wireless data communications equipment, video-game consoles, WEBTV, Internet telephony etc., all information through the network system can interact with appliances) and so on.

\section{The Design of Building Electrical Automation System}

When modern building automation system design, the principle to be followed is to fully functioning building electrical system, ensure the security of the building electrical equipment operation, so that each part of the reasonable combination, to maximize energy savings and human resource. In the specific design process designed primarily weak to do the design and coordination of the following aspects, including the design of lightning protection design of the building, the ground safety design of buildings, design of automatic fire alarm and linkage system, security system design cabling systems, communication network system design, information network system, designed to construction equipment monitoring system, cable television system design, PA system, echoing the design of signaling system design and public display devices, etc. Central management of confidential statistical collection building electrical automation system operation, alarm, performance, and optimize printing in one. Such centralized design, can effectively 
overcome conventional instrument control features a single-limiting and distribution control system after the dispersion difficult man-machine contact, shortcomings cannot be unified management. Intelligent Building ground electrical equipment design in the entire ground system design occupies a very important position and it is because the installation of electrical grounding system is reasonable relation to whether the whole building power supply system can operate safely.

Modern intelligent building construction, the design of the grounding system proposed new requirements, if it continues to follow based on the modern control theory basic statistical Distributed control systems, electronic devices can cause interference due to not work properly. Therefore, the modern intelligent building grounding system design must include the electronic device DC grounding system, safety grounding system, grounding system and exchange lightning protection grounding system. Performing electrical building automation system design must be in strict accordance with the instructions of the parent file, but also should follow the relevant design requirements of building units, but also a list of related process equipment. Conduct electrical building automation system design and construction time must be in accordance with national and relevant departments, procedures and standards for execution. In addition, the intelligent building is provided with anti-static requirements of the program-controlled switches, fire protection and fire control room, and some cannot be subject to electromagnetic interference of electronic equipment, based on these reasons, the intelligent building design but also design anti and anti-static shielding grounding system.

Electrification is an automated system designed to put all kinds of information for the entire mechanical and electrical equipment inside the building effectively classify, process and research, adopt the most optimized control technology, the content of each system can give a comprehensive and centralized management, the whole devices within the system are in an orderly, efficient coordination of operational status, to minimize the cost of each system.

\section{The Key of Application of Electrical Automation System in the Intelligent Building}

Electrical Grounding. When the inside of the building has no independent power distribution when the selection TN-S grounding system, TN-S grounding system is a three-phase four-wire cable plus PE, its main feature is the neutral wire $\mathrm{N}$ and protective earth the PE line, in addition to the common ground, the two no longer have any connection. In this system, the safety reference potential already has, in this case, you need only go to the art as long as the N-C-S system uses the same technology can be, it is possible to TN-S system as the grounding system of the building. With this grounding, the only computer in the building when there are no other special requirements.

The system consists of TN-C and TN-S two systems together whose interface is the connection point $\mathrm{N}$ line and $\mathrm{PE}$ line of the plane. It should be noted that, before entering the user needs to repeat the $\mathrm{TN}-\mathrm{C}$ system grounding, $\mathrm{TN}-\mathrm{C}$ system to repeat the ground after transformation into a TN-S system. For TN-C system, the main contents of the front has been introduced for the TN-S system, its main feature is the $\mathrm{N}$ line and $\mathrm{PE}$ line into the household at the time of a common ground, then there is no longer any connection. In this system, $\mathrm{N}$ line is often little state, PE line is never charged and TN-S system greatly improves security.

Electrical Protection. The so-called AC ground refers to the amount required to neutral on the transformer or made neutral point grounded. Here for grounded neutral material is required, it must be insulated copper wire. In this process it should be noted that the terminals of the auxiliary power distribution equipment and other potential not exposed, nor grounding systems and other hybrid junction. In the high-pressure system to ground the neutral point, mainly to ensure the relay is capable of precise reaction, there is an important role is to avoid the occurrence of residual voltage offset phenomenon, so well protected three phase voltage, and allowed to equilibrate.

Here that security is not grounded energized electrical equipment put on metal parts and metal grounding make a connection. Specific methods of operation process are inside the building near the equipment and construction area metal member all electricity, the use of PE cable to its good together. But remember not to put the $\mathrm{N}$ line and $\mathrm{PE}$ line together.

In the modern intelligent building will be used to a lot of computer equipment and 
communications equipment, when the input information of these devices, transformation, transmission and amplification and the final output is the potential use of micro-micro-current or high-speed conversion to complete, and between each device to complete the work over the Internet can be synergistic. To ensure accurate effectiveness of these devices work in the design, the first to be equipped with a stable power supply, also need to be equipped is stable reference potential. Lead material must be chosen insulated copper wire lines, and claims to have a larger cross-sectional area at one end of the wire to be connected to the reference potential and the other end to the DC grounding. In this process, we should remember not to be and the $\mathrm{N}$ line and PE line together.

Modern Intelligent Building because of its demand, there will be a lot of electronic equipment systems and a variety of wiring systems, electronic equipment and cabling in these systems, there are many parts of fear of lightning, lightning, these devices will bring great harm . For these reasons, in all cases the whole building functional ground carried out, as a first step should be the lightning protection and grounding work, and on this basis, but also to establish and improve the lightning protection system. Referring to building-related load level specifications, the building lightning protection system design should be designed in accordance with a lightning protection, a composition having a multi-layered shield cage lightning protection system.

\section{Conclusion}

Electric Automation System in Intelligent Building has a remarkable significance for the achievement of the modern intelligent building. Only in-depth understanding of key applications technology areas of electrification automation system in the intelligent building, can we be able to make the design of electrification automated systems and ensure safe and reliable operation of intelligent building equipment.

\section{References}

[1] Jia Xinzhang, Li Jingyuan. Electronic Industry, Vol. 6 (2014) No 53, p.25-26

[2] Peng Sue, Wang Yunhui, Wang Qunyong. Electrical Switch, Vol. 12 (2015) No 27, p.74-76

[3] Qian Xiyuan. Telecommunications Science, Vol. 30 (2014) No 19, p.144-145

[4] Wang Kuailiang. Electronic Industry, Vol. 29 (2011) No 27, p.21-23

[5] Zhang Gongxu, Sun Jing. Building Science, Vol. 8 (2013) No 27, p.57-60 